\title{
Biopreservation as a potential hurdle for Bacillus cereus growth in fresh cheese
}

\author{
Erica Tirloni, ${ }^{1 *}$ * Cristian Bernardi, ${ }^{1}$ Emilia Ghelardi, ${ }^{2,3}$ Francesco Celandroni, ${ }^{2}$ Christian Andrighetto, ${ }^{4}$ \\ Nicola Rota, ${ }^{5}$ and Simone Stella ${ }^{1}$ \\ ${ }^{1}$ Department of Health, Animal Science and Food Safety, Università degli Studi di Milano, Via Celoria 10, IT-20133, Milan, Italy \\ ${ }^{2}$ Department of Translational Research and New Technologies in Medicine and Surgery, University of Pisa, Via San Zeno 37, IT-56127, Pisa, Italy \\ ${ }^{3}$ Research Center Nutraceuticals and Food for Health-Nutrafood, University of Pisa, IT-56127, Pisa, Italy \\ ${ }^{4}$ Agenzia Veneta per l'Innovazione nel Settore Primario, Via San Gaetano 74, Thiene (VI), Italy \\ ${ }^{5}$ Freelance Agronomist, Pontirolo Nuovo, IT-24040, Italy
}

\begin{abstract}
This study aimed to evaluate the possible inhibitory effect of natural lactic acid bacteria on the growth of 2 Bacillus cereus strains. First, we evaluated the behavior of spores of $B$. cereus GPe2 and D43 when inoculated before cheesemaking using pasteurized or raw milk; no statistical differences were observed between cheese produced with the 2 types of milk. Then, lactic acid bacteria (LAB) were isolated from cheese at the last sampling time, identified, and tested in vitro for their antagonistic activity and organic acid production by using an HPLC method, showing antimicrobial potential. The LAB that produced larger inhibition halos $(>9 \mathrm{~mm}$ ) against $B$. cereus strains (LAB 3, 6, 9, 10: Lactococcus lactis ssp. lactis; LAB 7: Lactococcus lactis ssp. cremoris) were selected to produce a LAB mixture for subsequent tests. Spores of $B$. cereus GPe2 and D43 were inoculated in pasteurized milk before cheesemaking with or without addition of the LAB mixture at a high dosage. Bacillus cereus grew more slowly when LAB were added to the dairy matrix (with differences from 2.36 to $2.66 \mathrm{log} \mathrm{cfu} / \mathrm{g}$ in $B$. cereus GPe2 and D43 growth).
\end{abstract}

Key words: Bacillus cereus, competition, fresh cheese, organic acids, lactic acid bacteria

\section{INTRODUCTION}

The Bacillus cereus group is responsible for food spoilage, especially of dairy products (Bartoszewicz et al., 2008), but may also cause sporadic food poisoning (Dierick et al., 2005). Bacillus cereus is a common contaminant of raw milk, being frequently isolated

Received April 3, 2019.

Accepted September 3, 2019.

*Corresponding author: erica.tirloni@unimi.it from dairy products such as ice creams, milk powders, fermented milks, pasteurized milk, and ricotta (Wong et al., 1988; Granum et al., 1993; Carlin et al., 2000; Guinebretiere et al., 2001, 2003, 2008; Guinebretiere and Nguyen-The, 2003; Heyndrickx and Scheldeman, 2002; Arslan et al., 2014; Spanu et al., 2016). Raw milk is generally contaminated at the farm level by udders but the natural microbiota present in silo tanks, pasteurizers, and filling machines is also likely to play a role in post-pasteurization recontamination of milk (Svensson et al., 1999, 2000, 2004). In fact, endospores are able to resist and survive pasteurization heating, suggesting a potential hazard in pasteurized milk (Notermans et al., 1997; Bartoszewicz et al., 2008) and thus also in dairy products.

Mild preservation technologies are increasingly used in food industries, matching the requirement to minimize problems related to the presence of potential pathogenic bacteria or spoilage bacteria, including spore-forming microorganisms such as $B$. cereus. There is increasing interest in the use of biopreservative microorganisms and in particular of "generally regarded as safe" (GRAS) lactic acid bacteria (LAB), that have been shown to interfere with the growth of spoilage and pathogenic bacteria such as Listeria monocytogenes and B. cereus (Gálvez et al., 2008). The antimicrobial activity of LAB toward B. cereus was already shown in vitro by agar well-diffusion assay (Bogovič-Matijašić et al., 1998) and in sterile skim milk, in which 18 Lactobacillus and Lactococcus strains were tested and showed antimicrobial activity toward B. cereus strains (Røssland et al., 2003, 2005). Inhibition of $B$. cereus by LAB was also reported in nonfat milk medium (Wong and Chen, 1988), in Gouda and Brie cheese (Little and Knøchel, 1994; Rukure and Bester, 2001), and in Taleggio cheese and yogurt (Tirloni et al., 2017b).

In the present study, we evaluated the behavior of 2 $B$. cereus strains (one clinical isolate and a strain previously isolated from a dairy product) in fresh cheese 
produced from raw or pasteurized milk inoculated with spores before cheesemaking, thus mimicking the natural spore contamination of milk. Afterward, we investigated the antimicrobial activity of LAB strains isolated and identified from fresh cheese in vitro. Finally, we explored the behavior of the $2 \mathrm{~B}$. cereus strains by inoculating fresh cheese during production in coculture with a mixture of the previously selected LAB.

\section{MATERIALS AND METHODS}

\section{Part 1: Evaluation of Natural LAB Natural Microbiota on B. cereus Growth}

Bacterial Strains and Harvesting of Dormant Spores. In the present study, 2 B. cereus strains were used: one human clinical isolate (GPe2) able to grow from 15 to $37^{\circ} \mathrm{C}$ and to produce hemolysin $\mathrm{B}$, proteases, and phosphatidylcholine-specific phospholipase C (Celandroni et al., 2016). The production of phosphatidylcholine-specific phospholipase $\mathrm{C}$ was measured by a gel-diffusion assay with a gel containing crude phosphatidylcholine and protease secretion was assessed on an agar plate containing $1.5 \%$ skim milk. Strain GPe2 was shown to possess motility modes, such as swimming and swarming. The second strain was a food isolate (D43) collected from Taleggio cheese and able to grow from 15 to $37^{\circ} \mathrm{C}$, previously identified by MALDI-TOFMS (Tirloni et al., 2017b). The strain stock was kept frozen at $-80^{\circ} \mathrm{C}$ in Microbank cryogenic vials (Pro-Lab Diagnostics) until a loop of bacterial culture was subcultured into nutrient broth tubes (70122, Sigma, St. Louis, MO) and incubated at $37^{\circ} \mathrm{C}$ for $24 \mathrm{~h}$. Spores of the 2 strains were produced on fortified nutrient agar (Senesi et al., 1991) supplemented with the following sporulation salts: $\mathrm{NaCl}(5.0 \mathrm{mg} / \mathrm{mL}), \mathrm{CaCl}_{2},(0.1 \mathrm{mg} /$ $\mathrm{mL})$, and $\mathrm{MgSO}_{4} \cdot 7 \mathrm{H}_{2} \mathrm{O}(2.0 \mathrm{mg} / \mathrm{mL})$. Roux bottles with $150 \mathrm{~mL}$ of fortified nutrient agar were inoculated with $2.0 \mathrm{~mL}$ of spore suspension $\left(\sim 10^{7}\right.$ spores $/ \mathrm{mL}$ in distilled water). After incubation at $37^{\circ} \mathrm{C}$ for $20 \mathrm{~d}$, spores were scraped from the agar with a sterile stirrer and washed 5 times by centrifugation $(10,640 \times g$ for $10 \mathrm{~min}$ ) with ice-cold sterile distilled water. To remove residual vegetative cells, the 2 spore suspensions were heated at $80^{\circ} \mathrm{C}$ for $10 \mathrm{~min}$ in a water bath. Then, the suspensions were quickly cooled in ice, washed again in ice-cold sterile distilled water, and maintained at 2 to $4^{\circ} \mathrm{C}$ until use (within 3 d; Senesi and Ghelardi, 2010).

Growth Potential of $B$. cereus in Raw or Pasteurized Milk-Based Fresh Cheese. Raw and pasteurized cow milks were obtained on the same day of milking; pasteurized milk was obtained by vat pasteurization of the same raw milk by heat treatment: milk was heated in small batches at $65^{\circ} \mathrm{C}$ for $30 \mathrm{~min}$ and then rapidly cooled without homogenization. Raw and pasteurized milk were transported in refrigeration conditions to the laboratory and immediately used for fresh cheese production. Briefly, each type of milk (pasteurized and raw milk) was divided into 2 aliquots. Cheese was produced as reference without addition of any other ingredient that could interfere with the growth of Bacillus cereus and LAB (e.g., salt, preservatives). Each of the 4 final aliquots was heated to $38^{\circ} \mathrm{C}$ in a small cheesemaking tank and spores of 1 of the 2 $B$. cereus strains were added individually at a final concentration of 3 to $4 \mathrm{log} \mathrm{cfu} / \mathrm{mL}$. To minimize changes in product characteristics, the inoculum volume did not exceed $1 \%$ of the volume of the aliquots of milk $(\sim 5$ $\mathrm{L})$. Then, veal rennet was added ( $5 \mathrm{~mL}$ to each boiler) and the milk was mixed and kept for 30 min to obtain the curds. Then, the curds were cut with a knife in a cross-hatch pattern (several parallel cuts in one direction, followed by several perpendicular cuts to obtain squares of $16 \mathrm{~cm}^{2}$ ). The curds were left at 10 to 15 min at room temperature $\left(\sim 20^{\circ} \mathrm{C}\right)$ and then a second cut was made to obtain squares of $4 \mathrm{~cm}^{2}$ each. The curd was scooped slowly into cheese hoops and gently pressed into blocks to form the cheese. Cheese was left to drain at a temperature of $20^{\circ} \mathrm{C}$ for 10 to $15 \mathrm{~min}$; then, the formed cheese was turned to allow draining on the other surface for 10 to $15 \mathrm{~min}$. Finally, fresh cheese (50 g) was sealed in plastic trays without modified atmosphere packaging (MAP) conditioning and stored at $15^{\circ} \mathrm{C}$. Time zero corresponded to the moment when cheese drained and before packaging.

Microbiological Analyses. The 4 series of fresh cheese samples produced from pasteurized and raw milks were incubated at $15^{\circ} \mathrm{C}$ for $72 \mathrm{~h}$. During all trials, temperature was recorded regularly by data loggers (Escort iLog; Escort Data Logging System Ltd., Aesch Bei Birmensdorf, Switzerland). Samples of each series were submitted daily to microbiological analyses in duplicate. At each sampling time, $\mathrm{pH}$ was also measured (Amel Instrument, 334-B, Milan, Italy). From each inoculated sample, $10 \mathrm{~g}$ of product was diluted 10 -fold in chilled sterile diluent solution $(0.85 \% \mathrm{NaCl}$ and $0.1 \%$ peptone) and homogenized for $60 \mathrm{~s}$ in a Stomacher 400 (Seward Medical, London, UK). Then, serial 10-fold dilutions of the homogenates were made in chilled saline solution. Bacillus cereus were enumerated according to the ISO 7932:2004 method (ISO, 2004) by spreading onto polymyxin pyruvate egg-yolk mannitol-bromothymol blue agar (PEMBA) and incubating under aerobiosis at $37^{\circ} \mathrm{C}$ for $48 \mathrm{~h}$. All the media were provided by Biogenetics, Ponte San Nicolò, Italy. Spores were enumerated as previously described (Tirloni et al., 2017a). Briefly, homogenates were heated at $80^{\circ} \mathrm{C}$ for 10 min before being plated on PEMBA and incubated 
under aerobiosis at $37^{\circ} \mathrm{C}$ for $48 \mathrm{~h}$. The same samples were submitted to determination of total viable count excluding LAB, which was determined on gelatin peptone bios agar (Biogenetics, Ponte San Nicolò, Italy), and for Pseudomonas spp. (ISO/TS 11059:2009; ISO, 2009) on Pseudomonas agar base supplemented with Cetrimide Fucidin Cephalosporin supplement incubated for $48 \mathrm{~h}$ at $30^{\circ} \mathrm{C}$. Coagulase-positive staphylococci were enumerated on Baird Parker agar incubated at $37^{\circ} \mathrm{C}$ for $48 \mathrm{~h}$ (ISO 6888:1999; ISO, 1999) and LAB on de Man, Rogosa, and Sharpe (MRS) agar (Oxoid, Basingstoke, UK) incubated under anaerobiosis at $30^{\circ} \mathrm{C}$ for 48 h (ISO 15214:1998; ISO, 1998).

\section{Part 2: Antimicrobial Activity of LAB Isolated from Cheese}

Isolation and Identification of Natural Microbiota. From the plates used for LAB counts of fresh cheese samples produced from raw milk and stored for $72 \mathrm{~h}, 5$ colonies from GPe2-inoculated cheese and 5 colonies from D43-inoculated cheese were randomly picked and submitted to biochemical tests: isolates were tested for Gram reactions by $\mathrm{KOH}$ method and for standard cytochrome oxidase (Oxoid) and catalase reactions. Afterward, random amplified polymorphic DNA (RAPD)-PCR was performed as described by Andrighetto et al. (2002) and Soto del Rio et al. (2016) in strain D43 by using M13 and D11344 primers. Isolates were identified at the species level by means of species-specific PCR and by sequencing $(\mathrm{Pu}$ et al., 2002) and by sequencing the V1-V3 region of the $16 \mathrm{~S}$ rDNA.

Antimicrobial Activity. Bacillus cereus GPe2 and D43 and the $10 \mathrm{LAB}$ isolates (LAB 1 to 10) were stored in cryovials (Microbank, Pro-Lab Diagnostics) until use. Each of the LAB isolates was sub-cultured in MRS broth tubes (Oxoid) and incubated at $30^{\circ} \mathrm{C}$ for $48 \mathrm{~h}$ under anaerobiosis (Anaerojar, Oxoid). A volume of $100 \mu \mathrm{L}$ of each LAB broth culture was individually reinoculated in 10-mL MRS broth tubes and incubated at $30^{\circ} \mathrm{C}$ for $48 \mathrm{~h}$ under anaerobiosis. The optical density at $540 \mathrm{~nm}\left(\mathbf{O D}_{540}\right)$ was recorded just after inoculation and precultures were collected in exponential growth phase (when OD was close to 0.5/0.7). After incubation, the OD was adjusted by dilution (about 0.5) and spotted with a sterile swab (Carlo Erba, Rodano, Italy) onto the surface of MRS agar plates, which were subsequently incubated for $48 \mathrm{~h}$ at $30^{\circ} \mathrm{C}$ anaerobically. Each of the $2 \mathrm{~B}$. cereus strains was sub-cultured aerobically overnight at $37^{\circ} \mathrm{C}$ in $10-\mathrm{mL}$ tryptic soy broth (TSB) tubes (Oxoid). The test was performed according to Tirloni et al. (2014); briefly, $\mathrm{OD}_{540}$ was recorded at the time of incubation and precultures were collected in exponential growth phase, defined as a relative change in absorbance of at least 0.2 at $540 \mathrm{~nm}$. If needed, samples were diluted before performing the tests. For each microorganism, $0.2 \mathrm{~mL}$ of bacterial suspension was added to a 5-mL aliquot of semisolid agar [brain heart infusion broth (Oxoid) plus agar 0.7\%], maintained at $45^{\circ} \mathrm{C}$, and then poured over the MRS plates previously spotted with LAB. After incubation at $37^{\circ} \mathrm{C}$ for $24 \mathrm{~h}$, the plates were checked (Tirloni et al., 2014). A clear halo around the LAB spot indicated the inhibition of the pathogen. Mean radius of the halos were measured and expressed in millimeters.

To define whether pathogen inhibition was due to the production of antagonistic compounds, the LAB cell-free supernatants were tested against the same pathogens. Each LAB was sub-cultured in MRS broth. After $48 \mathrm{~h}$ of incubation, an aliquot of each culture was centrifuged at $10,640 \times g$ for $10 \mathrm{~min}$. Supernatants were then filtered using $0.2-\mu \mathrm{m}$ filters (Sacco, Cadorago, Italy) and maintained at $4^{\circ} \mathrm{C}$. The $\mathrm{pH}$ of supernatants was also measured using a $\mathrm{pH}$ meter (XS pH6, Ghiaroni, Buccinasco, Italy). Each of the $B$. cereus strains was inoculated into $10-\mathrm{mL}$ TSB tubes and incubated as described above. Then, $1 \mathrm{~mL}$ of inoculated TSB was transferred into flasks containing 25 $\mathrm{mL}$ of tryptic soy agar (Oxoid), maintained at $45^{\circ} \mathrm{C}$, carefully mixed, and poured onto sterile Petri plates (Carlo Erba). According to the method of Tirloni et al. (2014), once the medium solidified, blank discs (Oxoid) were dipped in the supernatant of each LAB, placed on the surface of the plates, and incubated at $37^{\circ} \mathrm{C}$ for 24 h. Clear zones around the discs were measured. If inhibition was recorded, to evaluate whether it was related to the ability to produce organic acids, the $\mathrm{pH}$ of cellfree supernatants was adjusted to 6.5 with $\mathrm{NaOH}(1 \mathrm{~N}$; Sigma, Milan, Italy) and the same test was repeated. All the tests were performed in triplicate.

Production of Lactic and Acetic Acids. Each LAB was sub-cultured in MRS broth. After $48 \mathrm{~h}$ of incubation, organic acids were quantified using HPLC according to Tormo and Izco (2004): briefly, $1.0 \mathrm{~g}$ of MRS broth inoculated individually with each of the $10 \mathrm{LAB}$ was diluted to $5.0 \mathrm{~mL}$ in water and vigorously vortexed for $20 \mathrm{~s}$. After centrifugation $(3,000 \times g, 15 \mathrm{~min})$, the supernatant was filtered through a $0.45-\mu \mathrm{m}$ cellulose membrane. The HPLC system consisted of 2 pumps (Waters 510, Waters, Milan, Italy), an auto-sampler (Waters 717 plus), and a UV-Vis detector (Waters 484) set at $210 \mathrm{~nm}$. According to Tirloni et al. (2018), separation was performed on a Rezex ROA column (300 $\mathrm{mm} \times 7.8 \mathrm{~mm}, 8 \mu \mathrm{m}$; Phenomenex, Torrance, CA).

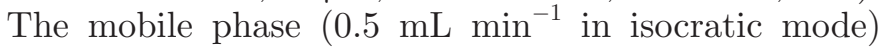


was $0.005 N$ sulfuric acid. External standards were used for identification and quantification of acetic and lactic acids. The limit of detection $(0.076$ and $0.24 \mathrm{mM}$ for acetic and lactic acids, respectively) and limit of quantification (0.39 and $0.77 \mathrm{mM}$ for acetic and lactic acids, respectively) were determined. The limits of detection and quantification were calculated by using the signalto-noise approach (EMEA, 1995).

\section{Part 3: Effect of LAB Mixture Inoculated in Fresh Cheese Against B. cereus}

The LAB strains showing the most effective inhibitory activity in terms of halos produced against $B$. cereus strains were selected for this part of the trial. A loop of frozen culture of each LAB strain was transferred to a test tube containing $10 \mathrm{~mL}$ of MRS broth (Oxoid) and incubated for $48 \mathrm{~h}$ at $30^{\circ} \mathrm{C}$ under anaerobiosis. All strains were reinoculated into refrigerated MRS broth tubes and the initial $\mathrm{OD}_{540}$ was measured. Then, all tubes were incubated at $15^{\circ} \mathrm{C}$ and $\mathrm{OD}$ was measured after $48 \mathrm{~h}$. The bacterial cells were pelleted by centrifugation at $10,640 \times \mathrm{g}$ for $10 \mathrm{~min}$ at $4^{\circ} \mathrm{C}$ and washed in PBS, pH 7.0. The cell density of each LAB strain was determined by microscopy $(1,000 \times$; Meiji Techno America, San Jose, CA). As needed, precultures were diluted in $0.85 \% \mathrm{NaCl}$ solution to obtain
$8 \log \mathrm{cfu} / \mathrm{mL}$ suspensions before inoculating the milk used to produce fresh cheese. A LAB mixture of the most inhibiting strains selected was prepared by adding the same amount of each strain at a final concentration of 5 to $6 \log \mathrm{cfu} / \mathrm{mL}$. Finally, fresh cheese was produced as described above. Before heating the cultures to $38^{\circ} \mathrm{C}$, spores of the $2 \mathrm{~B}$. cereus strains were individually inoculated at a final concentration of 3 to $4 \log \mathrm{cfu} / \mathrm{mL}$, and the mixture of LAB was added immediately after. The fresh cheese samples obtained were stored at $15^{\circ} \mathrm{C}$ and sampled immediately after inoculation (T0) and again after 24, 48, and $72 \mathrm{~h}(\mathbf{T} \mathbf{1}, \mathbf{T} 2$, and $\mathbf{T 3}$, respectively) in duplicate. Bacillus cereus and its spores and LAB were enumerated as described above.

The concentrations of organic acids produced during the trial were determined by HPLC (Tormo and Izco, 2004; Tirloni et al., 2018). Briefly, $1.0 \mathrm{~g}$ of fresh cheese was diluted to $5.0 \mathrm{~mL}$ in water and vigorously mixed by vortex for $20 \mathrm{~s}$. After centrifugation $(3,000$ $\times g ; 15 \mathrm{~min})$, the supernatant was filtered through a $0.45-\mu \mathrm{m}$ cellulose membrane. The analyses (enumeration of spores and vegetative cells + spores of B. cereus, enumeration of LAB) were performed in duplicate on fresh cheese produced at T0, T1, T2, and T3. Moisture (Bradley and Vanderwarn, 2001) and pH (334-B, Amel Instrument, Milan, Italy) were determined at each sampling time in duplicate.

\section{B. cereus D43}

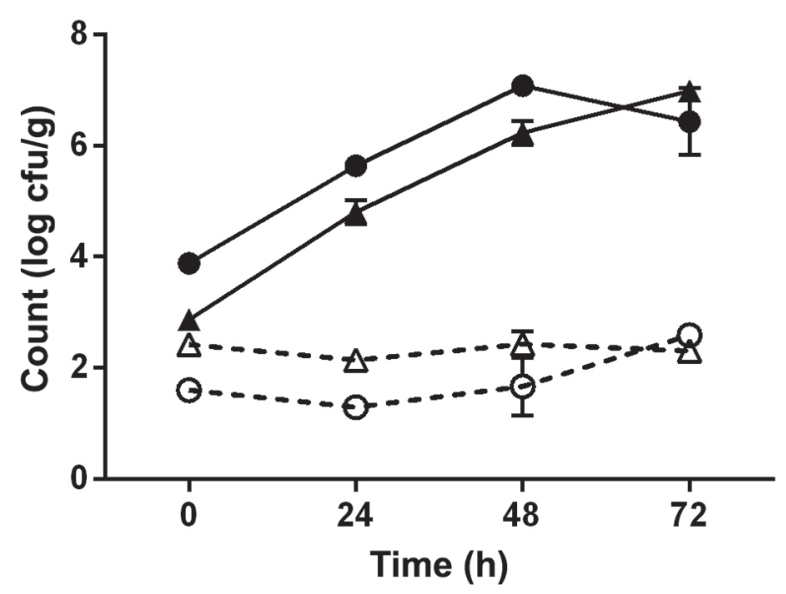

B. cereus $\mathrm{GPe2}$

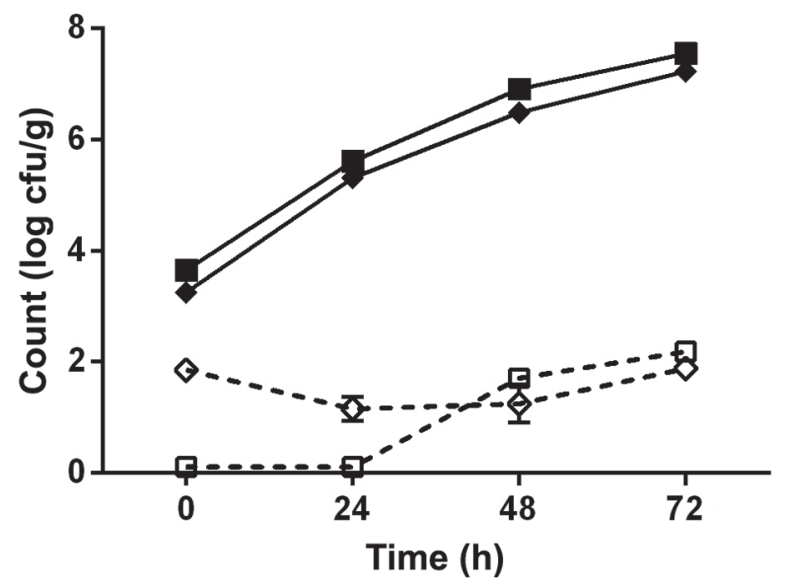

Figure 1. Growth of spores and spores + vegetative cells of Bacillus cereus GPe2 and D43 in fresh cheese made from raw and pasteurized milk during $72 \mathrm{~h}$ at $15^{\circ} \mathrm{C}$ (trial performed in duplicate). Error bars indicate SD. 
Table 1. Counts of total viable bacteria, lactic acid bacteria (LAB), Pseudomonas spp., Escherichia coli, enterococci, and coagulasepositive staphylococci in raw milk used for trial 1

\begin{tabular}{lc}
\hline Parameter & Count $(\log \mathrm{cfu} / \mathrm{g})$ \\
\hline Total viable count & $2.50 \pm 0.21$ \\
LAB & $3.34 \pm 0.24$ \\
Pseudomonas spp. & $<2$ \\
Escherichia coli & $<2$ \\
Enterococci & $<2$ \\
Coagulase-positive staphylococci & $<2$ \\
\hline
\end{tabular}

\section{Statistical Analysis}

Data obtained from the $B$. cereus counts and LAB counts (expressed as $\Delta \log \mathrm{cfu} / \mathrm{g}$ between sampling time and T0) and the increase in organic acid concentrations were submitted to 2-way univariate ANOVA in SAS (version 9.1, 2016; SAS Institute Inc., Cary, NC) to reveal potential differences in the behavior of the 2 strains. Threshold values for statistical significance were set at $P<0.05$ and $P<0.01$.

\section{RESULTS AND DISCUSSION}

\section{Part 1: Evaluation of Natural LAB Microbiota on B. cereus Growth}

In the first part of this study, we assessed the ability of 2 B. cereus strains (GPe2 and D43) to grow in fresh cheese by deliberate contamination with spores of the milk (raw and pasteurized) used for cheese production (Figure 1). Spores of the 2 B. cereus strains were able to germinate and bacterial growth occurred rapidly after inoculation during cheesemaking in the fresh cheese obtained from raw and pasteurized milk. This finding confirmed that, following mild heat treatment, activation instead of inactivation of dormant spores occurred, possibly increasing pathogen outgrowth and the risk of food poisoning (Kim and Foegeding, 1990; Van Opstal et al., 2004).
Raw milk was previously recognized to have a strong typical antimicrobial activity due to the multifactorial competitive action of the resident natural microbiota that includes several strains of LAB. This antagonistic effect has been reported for $L$. monocytogenes and $B$. cereus (Lianou and Samelis, 2014; Montel et al., 2014; Tirloni et al., 2017b). In terms of postcontamination, as stated in previous works, pasteurized and thermized milk would experience faster growth of pathogens if compared with raw milk; LAB, in fact, act as competitors in the bacterial growth. If a contamination of raw materials or a postcontamination occurs with spores, these spores may be activated by a subsequent heating (Samelis et al., 2009). In this study, the lack of difference between the 2 cheese types could be because the natural microbiota (mainly LAB) was only partially inactivated by pasteurization. Raw milk was characterized by very low total viable count $(\sim 2 \log$ $\mathrm{cfu} / \mathrm{mL}$ ); LAB showed values around 3 to $4 \log \mathrm{cfu} / \mathrm{mL}$, whereas other bacteria of interest (Pseudomonas spp., Escherichia coli, enterococci, and coagulase-positive staphylococci) were below the detection limit of $2 \log$ $\mathrm{cfu} / \mathrm{mL}$ (Table 1).

At the beginning of the trial, LAB counts in raw and pasteurized milk cheese were almost equivalent (3.26-3.58 vs. $3.47-3.69 \mathrm{log} \mathrm{cfu} / \mathrm{g}$ in pasteurized and raw milk cheeses, respectively), whereas at the end of the trial, counts in raw milk cheese were almost 1 log higher (8.18-8.30 vs. $7.22-7.51 \mathrm{log} \mathrm{cfu} / \mathrm{g})$. Pseudomonas spp. and coagulase-positive staphylococci were below the detection limit in raw and pasteurized milk, whereas the total viable counts were never high (always $<4 \log \mathrm{cfu} / \mathrm{g}$ ); in such conditions, significant antagonistic activity was not confirmed.

The RAPD-PCR results (Figure 2) indicated that the LAB population of the raw milk was dominated by Lactococcus lactis; 7 of 10 colonies isolated grouped with the type strain of Lactococcus lactis ssp. lactis, showing a similarity level of $52 \%$ and 6 different ampli-
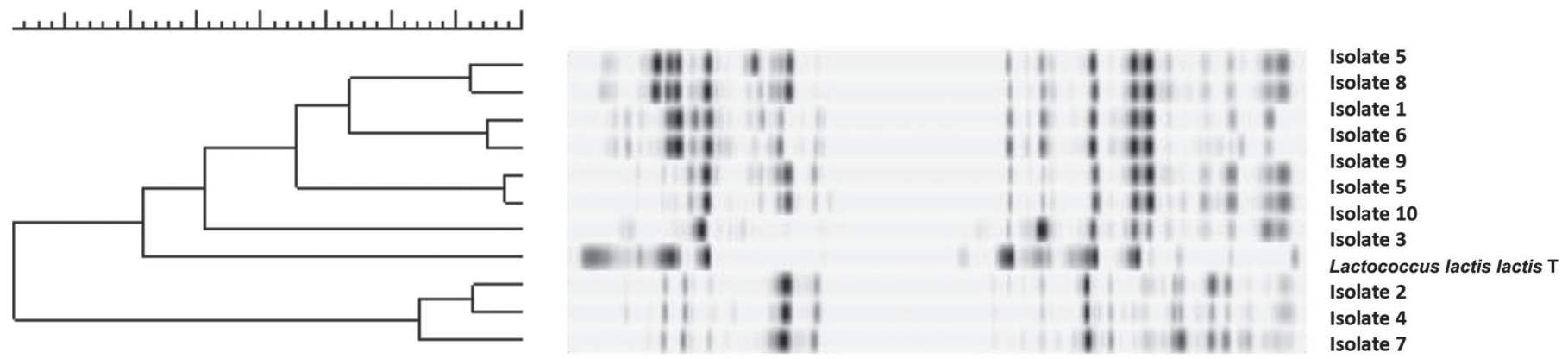

Figure 2. Dendrogram obtained from random amplified polymorphic DNA (RAPD)-PCR analysis with primers M13 and D11344 of 10 lactic acid bacteria strains isolated for cheese produced from raw milk. 


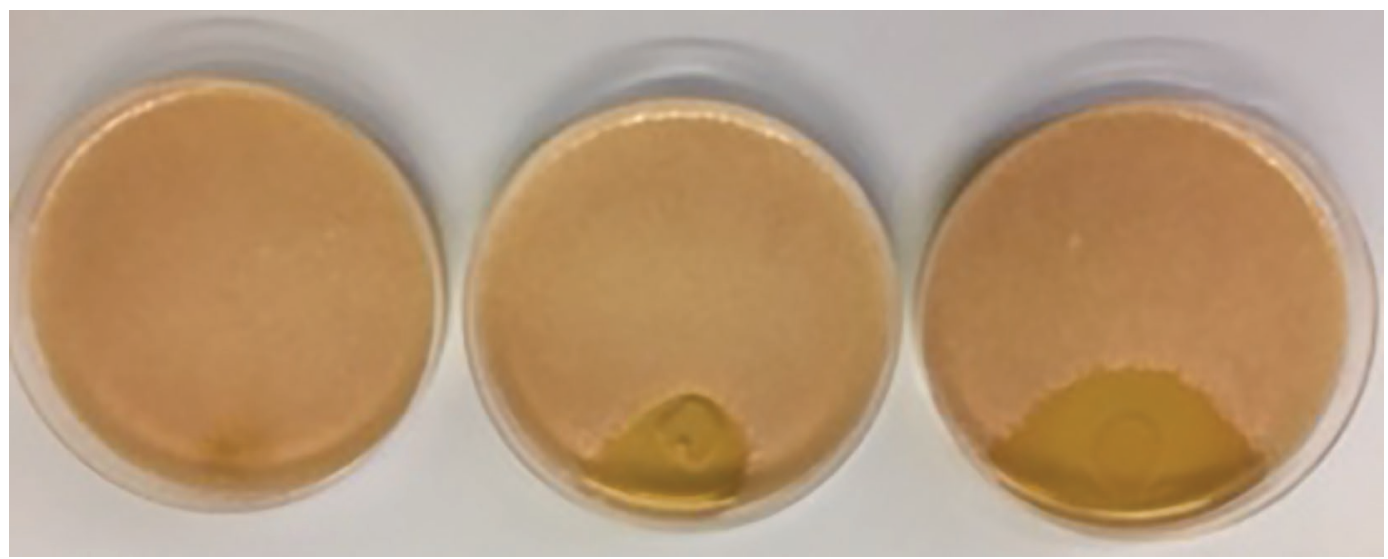

Figure 3. Clear halos produced by antagonistic activity of Lactococcus strains lactic acid bacteria (LAB) 3 (left), LAB 8 (middle), and LAB 1 (right) against Bacillus cereus GPe2 after incubation at $37^{\circ} \mathrm{C}$ for $24 \mathrm{~h}$.

fication profiles. These colonies were confirmed as Lactococcus lactis ssp. lactis by means of species-specific PCR. The other 3 colonies grouped at a similarity level of $85 \%$, showing 2 different amplification profiles, and were identified as L. lactis ssp. cremoris by means of $16 \mathrm{~S}$ rDNA V1-V3 region sequencing. Lactococcus lactis is the most important Lactococcus species for the dairy industry (Cavanagh et al., 2015) and has been widely used as a natural or commercial starter or added to dairy products or other fermented milk products to confer a typical flavor.

\section{Part 2: Antimicrobial Activity of LAB Isolated from Cheese}

The role of $\mathrm{LAB}$ as potential biopreservatives in fresh cheese was shown by the $10 \mathrm{LAB}$ identified and tested in this study. When tested on agar plates (Figure 3), 7 LAB isolates were able to inhibit the growth of both $B$. cereus strains; 2 additional strains (belonging to $L$. lactis ssp. lactis) were active only against the GPe2 strain. The mean radius of the inhibition halos obtained are reported in Table 2. The GPe2 strain was generally more susceptible to LAB inhibition than the D43 strain (except for L. lactis ssp. cremoris LAB 4, profile $\mathrm{G}$ ), as confirmed by the statistical analysis (the results by LAB 3, 6, 9, and 10 were significantly higher). Two of the L. lactis ssp. lactis tested (LAB 9 and LAB 10), both belonging to profile E, produced halos with diameters $>10 \mathrm{~mm}$ against $\mathrm{GPe} 2$, and 2 L. lactis ssp. lactis strains (LAB 3 and LAB 6, profiles $\mathrm{F}$ and D, respectively) and 2 L. lactis ssp. cremoris (LAB 2 and 7, profiles $\mathrm{G}$ and $\mathrm{H}$, respectively) produced inhibition halos of 8.5 to $9.5 \mathrm{~mm}$.

Table 2. Radius (mean $\pm \mathrm{SD} ; \mathrm{mm}$ ) of inhibition halos produced by each of the lactic acid bacteria (LAB) strains (Lactococcus lactis) and relative supernatant against the Bacillus cereus target strains, $\mathrm{pH}$, and lactic acid production after $48 \mathrm{~h}^{\mathrm{I}}$

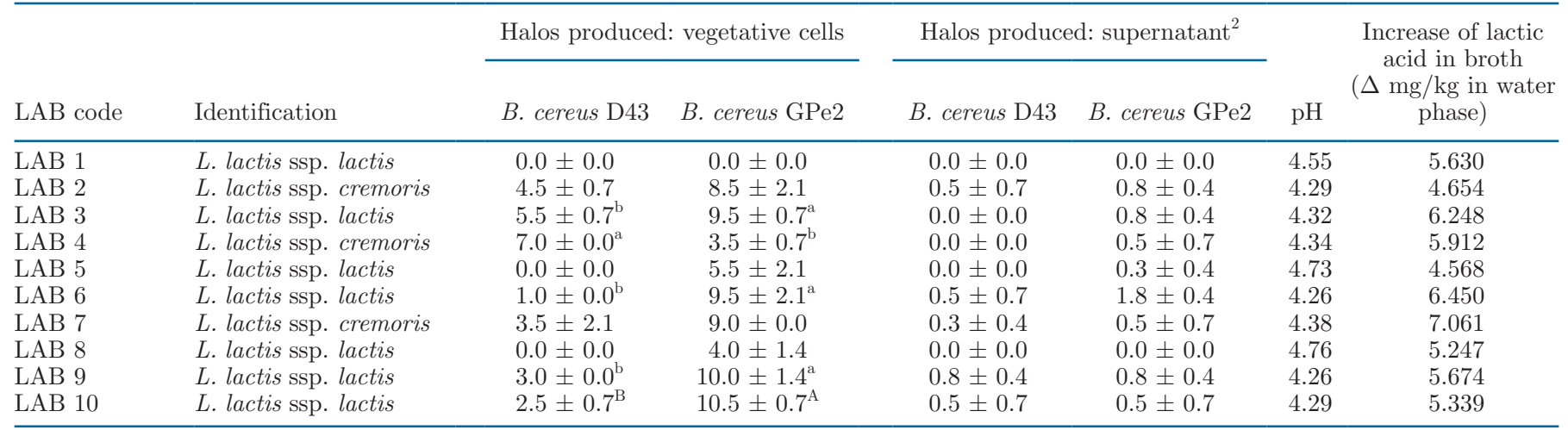

\footnotetext{
${ }_{\mathrm{A}, \mathrm{B}}$ Statistically significant difference among the sampling times $(P<0.01)$.

${ }^{\mathrm{a}, \mathrm{b}}$ Statistically significant difference among the sampling times $(P<0.05)$.

${ }^{1}$ The mean radius of the inhibition halos was calculated as the distance from the spotted inoculum and the growth of target microorganism.

${ }^{2}$ Supernatant was obtained by centrifugation of the broth in which LAB were grown.
} 
Very slight inhibition of the $2 B$. cereus strains was exerted by the 10 LAB supernatants compared with the inhibition by viable LAB strains (Table 2). Also, D43 was more resistant than GPe2, although not significantly so. The most effective LAB strains were LAB $2,3,4,6,9$, and 10. Generally, the slight inhibition exerted by supernatants indicated that the antimicrobial effect mainly originated from a combination of bacterial competition and the production of extracellular compounds, such as organic acids. This was reflected by the lower $\mathrm{pH}$ in the supernatants of LAB cultures 2 , $3,6,9$, and 10 .

The quantification of organic acids in LAB cell cultures confirmed these results (Table 3); lactic acid was the main end product of LAB metabolism, although LAB also produce minor quantities of other organic acids such as acetic, formic, and butyric acids (Passerini et al., 2013; Alegria et al., 2016). In our tests, acetic and citric acids did not show any trend of increase or decrease after incubation of broths (citric acid: T0 $=$ $1,866 \pm 148 \mathrm{mg} / \mathrm{kg}, \mathrm{T} 2=1,794 \pm 74 \mathrm{mg} / \mathrm{kg}$; acetic acid: $\mathrm{T} 0=259 \pm 41 \mathrm{mg} / \mathrm{kg}, \mathrm{T} 2=214 \pm 13 \mathrm{mg} / \mathrm{kg}$ ). For lactic acid, a clear increase was detected, with a mean value at $\mathrm{T} 0$ of $8,773 \pm 406 \mathrm{mg} / \mathrm{kg}$ that increased to $14,451 \pm 751 \mathrm{mg} / \mathrm{kg}$ at $\mathrm{T} 2(P<0.01)$. The increase in lactic acid concentration obtained for each $\mathrm{LAB}$ strain is shown in Table 2: the strains that increased more were LAB 7 (L. lactis ssp. cremoris) followed by LAB 6 and 3 (both L. lactis ssp. lactis). No statistical differences were found among the 10 strains tested.

\section{Part 3: Effect of LAB Mixture Inoculated in Fresh Cheese Against B. cereus}

The LAB that had the highest antimicrobial activity (i.e., those that produced larger halos: LAB 3, 6, 9, 10: L. lactis ssp. lactis; LAB 7: L. lactis ssp. cremoris) were selected to produce the LAB mixture used to test the bioprotective effect of $\mathrm{LAB}$ in cheese.

A significantly higher increase in counts was revealed for the $2 \mathrm{~B}$. cereus strains in fresh cheese made with pasteurized milk without the adjunct of the LAB mixture (Figure 4; $P<0.01$ ). Bacillus cereus GPe2 was inhibited by the action of the LAB mixture, as demonstrated by the significantly slower growth $(P<$ 0.01 from $\mathrm{T} 1$ to the end of the trial) detected during the whole trial that resulted in maximum growth rate $\left(\mu_{\max }\right)$ of 0.219 and $0.116 \mathrm{log} \mathrm{cfu} / \mathrm{h}$ in fresh cheese inoculated with GPe2 or with GPe2 + LAB, respectively. This trend resulted in a difference in growth of $2.36 \mathrm{log}$ cfu/g after $72 \mathrm{~h}$ (Figure 4). This effect could be attributed to the early conditioning of the dairy matrix by the $\mathrm{LAB}$ mixture ( $\mathrm{LAB}$ concentrations at $\mathrm{T} 0=5.98$ vs. $3.22 \mathrm{log} \mathrm{cfu} / \mathrm{g}$ in cheese produced with and without the

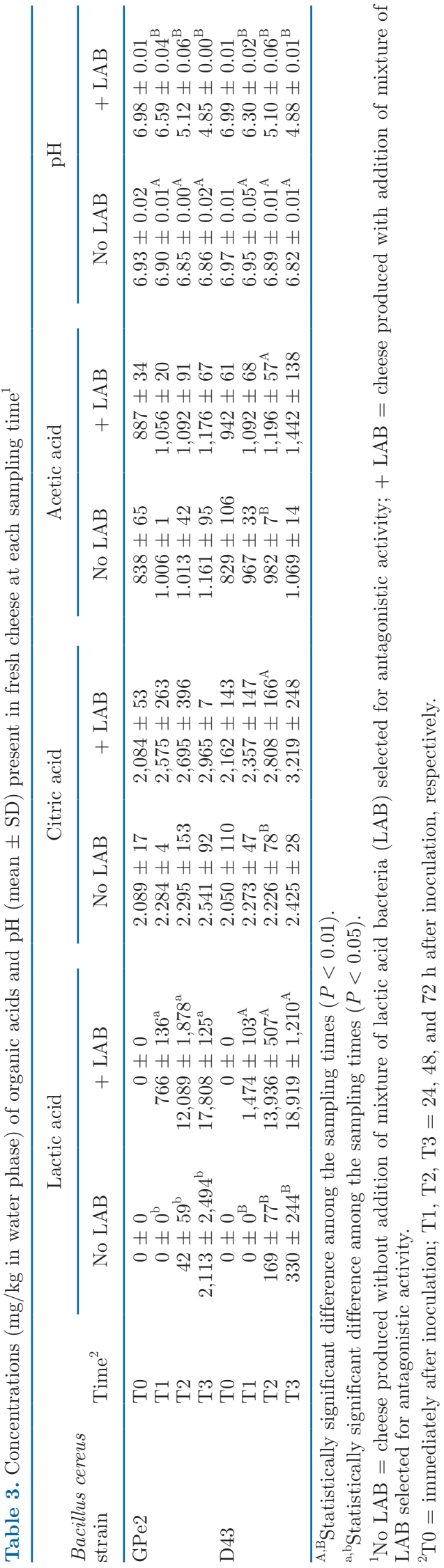


addition of $\mathrm{LAB}$, respectively). In fact, the LAB load reached 9.17 and $5.80 \mathrm{log} \mathrm{cfu} / \mathrm{g}$ at $\mathrm{T} 3$ in cheese with and without addition of the LAB mixture, respectively.
The number of $B$. cereus spores remained constant throughout sampling, with no statistical differences between samples inoculated with $B$. cereus and those
* LAB
D43 vegetative cells + spores
$\Theta$ D43 spores

\section{D43}

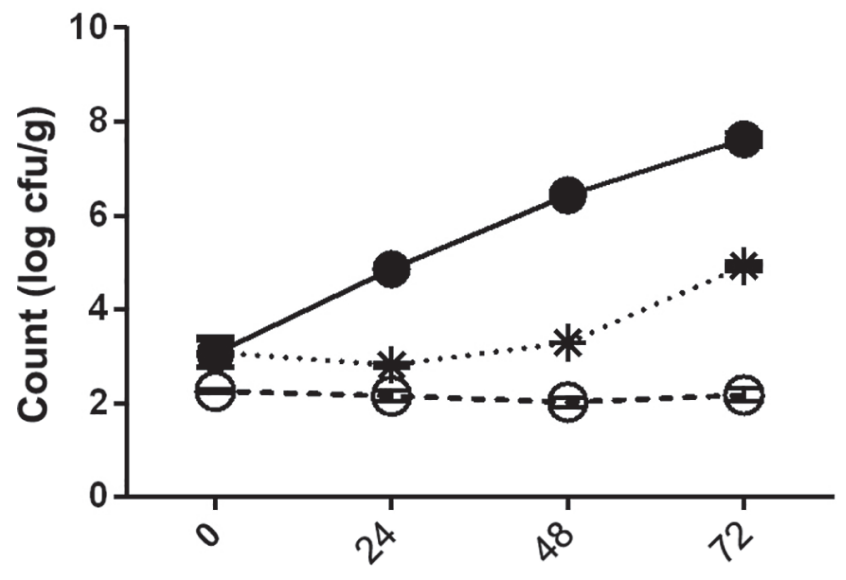

* *AB

GPe2 vegetative cells + spores

$\diamond$ GPe2 spores

\section{$\mathrm{GPe} 2$}

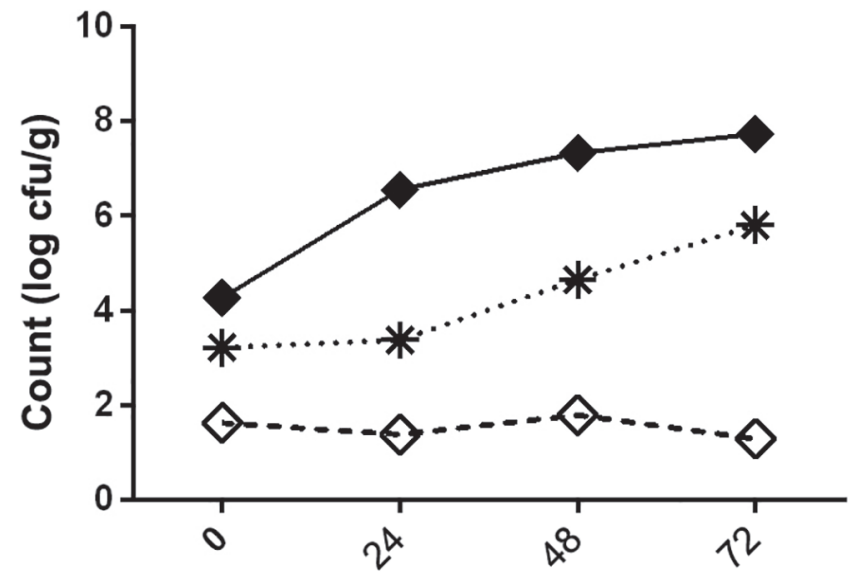

Time (h)

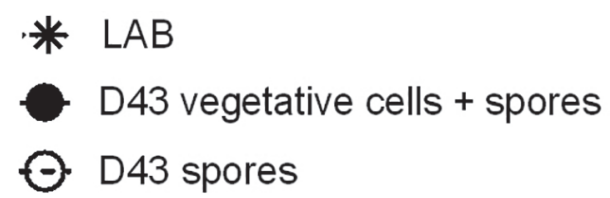

D43 + LAB
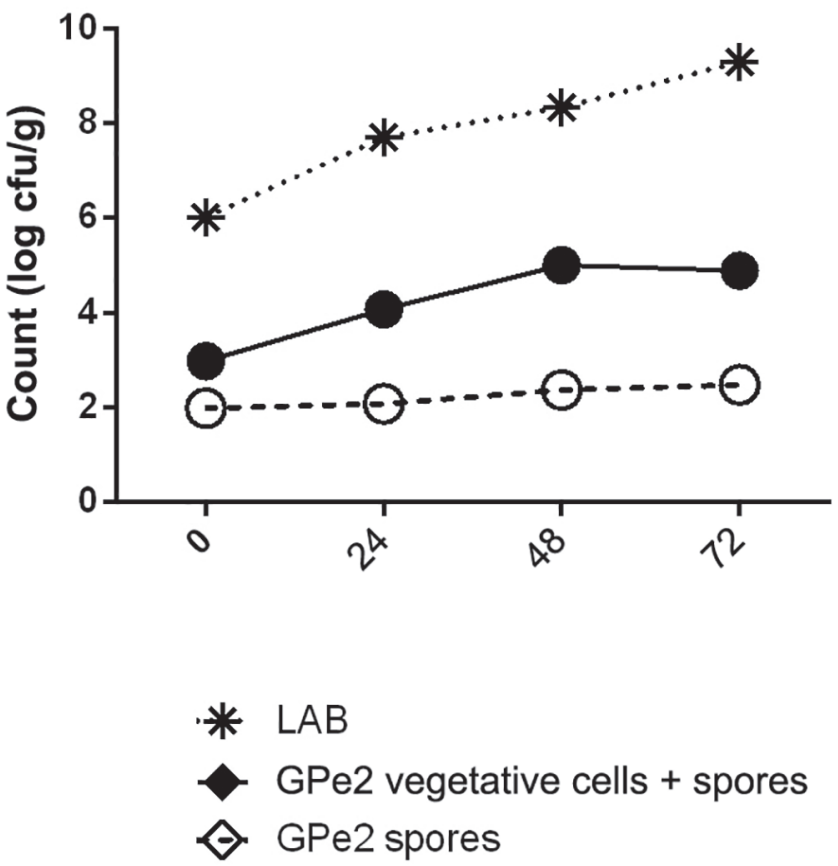

GPe2 + LAB

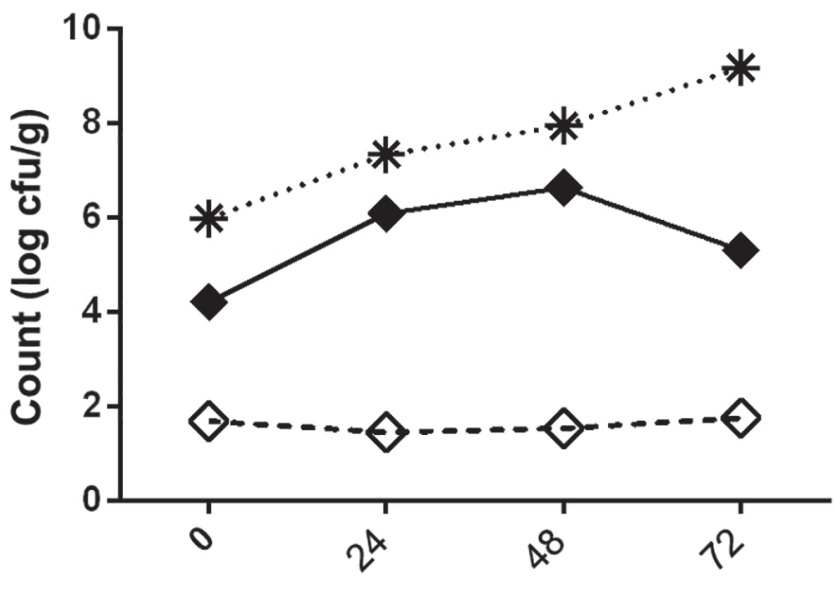

Time (h)

Figure 4. Growth of spores and spores + vegetative cells of Bacillus cereus GPe2 and D43 in fresh cheese with or without addition of lactic acid bacteria (LAB) cultures during $72 \mathrm{~h}$ at $15^{\circ} \mathrm{C}$. 
with the LAB mixture, suggesting rapid germination during cheesemaking.

In the trial performed with $B$. cereus $\mathrm{D} 43$-inoculated cheese, the pathogen was clearly inhibited by the presence of the LAB mixture; significantly slower growth was detected $\left(\mu_{\max }=0.164\right.$ and $0.109 \log \mathrm{cfu} / \mathrm{h}$ in fresh cheese inoculated with $B$. cereus D43 and with D43 $+\mathrm{LAB}$, respectively), resulting in significantly lower concentrations for the whole period $(P<0.01$ from $\mathrm{T} 1$ to the end of the trial). This led to a difference in growth of $2.66 \mathrm{log} \mathrm{cfu} / \mathrm{g}$ after $72 \mathrm{~h}$ (Table 3 ) among the 2 sets of samples. As reported for GPe2, LAB showed a rapid increase during the period, resulting in significantly higher counts in samples with the LAB mixture (Figure 4).

The inhibition of specific bacterial populations (in this case, B. cereus) due to the rapid growth of natural or added natural microbiota (LAB) is a well-known phenomenon in food matrices, a phenomenon named the "Jameson effect"; Jameson (1962) observed Escherichia coli inhibition by Salmonella when the maximum population density of Salmonella spp., present at a higher concentration in the substrate, was reached. This has been observed in many dairy products and nondairy foods, where nutrients were depleted by growth of the natural microbiota, thus restricting growth of other bacteria present (Mellefont et al., 2008; Møller et al., 2013; Østergaard et al., 2014). This represents a fundamental mechanism to ensure the safety of various foodstuffs. This event has been hypothesized for $B$. cereus inoculated in dairy matrices characterized by the presence of natural or natural starter microbiota (Tirloni et al., 2017b).

In this trial, the inhibition of $B$. cereus growth by $\mathrm{LAB}$ revealed by the challenge tests data could be related to the depletion of nutrients. The production of active compounds by LAB may also be assumed, as demonstrated by the decrease in $\mathrm{pH}$ value as a result of the large increase in lactic acid produced when LAB mixture was added (from a concentration below the detection limit at T0 to $\sim 18,000 \mathrm{mg} / \mathrm{kg}$ after $72 \mathrm{~h}$ of storage at $15^{\circ} \mathrm{C}$ ). Contextually, the increase in lactic acid content in GPe $2+\mathrm{LAB}$ and $\mathrm{D} 43+\mathrm{LAB}$ fresh cheese was followed by $\mathrm{pH}$ decrease (from 6.98 and 6.99 to 4.85 and 4.88 , respectively, $P<0.01$; Table 3 ), which was not detected in samples without the added LAB mixture. These results confirmed analogous antagonistic effects shown by the natural microbiota observed in raw milk (Tirloni et al., 2017a). Finally, the production of citric and acetic acids seemed to have a secondary role in the environment conditioning: low concentrations were detected for both acids, with a constant level for citric acid and a slight increase in acetic acid concentration during the trial.

\section{CONCLUSIONS}

In the present study, LAB strains isolated from dairy substrate were able to inhibit $B$. cereus growth in fresh cheese, especially when species-specific LAB were added at a high starting dosage, thus conditioning the dairy matrix from the beginning of the storage period. The selection of LAB as potential biopreservatives for future application in food matrices is principally based on their antagonistic activity, but other aspects should be further investigated, such as acidification of the substrate. Future research should consider selection of strains that combine antagonistic efficacy with minimal sensorial effects.

\section{ACKNOWLEDGMENTS}

This study was supported by Department of Health, Animal Science and Food Safety, Università degli Studi di Milano (Milan, Italy; Piano Sviluppo Ricerca 2016 Linea 2 Azione B).

\section{REFERENCES}

Alegria, A., P. Gonzales, S. Delgado, A. B. Florez, A. M. HernandezBarranco, A. Rodriguez, and B. Mayo. 2016. Characterisation of the technological behaviour of mixtures of mesophilic lactic acid bacteria isolated from traditional cheese made of raw milk without added starters. Int. J. Dairy Technol. 69:507-519.

Andrighetto, C., F. Borney, A. Barmaz, B. Stefanon, and A. Lombardi. 2002. Genetic diversity among Streptococcus thermophilus strains isolated from Italian traditional cheese. Int. Dairy J. 12:141-144.

Arslan, S., A. Eyi, and R. Küçüksarı. 2014. Toxigenic genes, spoilage potential, and antimicrobial resistance of Bacillus cereus group strains from ice cream. Anaerobe 25:42-46.

Bartoszewicz, M., B. M. Hansen, and I. Swiecicka. 2008. The members of the Bacillus cereus group are commonly present contaminants of fresh and heat-treated milk. Food Microbiol. 25:588-596.

Bogovič-Matijašić, B., I. Rogelj, I. F. Nes, and H. Holo. 1998. Isolation and characterization of two bacteriocins of Lactobacillus acidophilus LF221. Appl. Microbiol. Biotechnol. 49:606-612.

Bradley, R. L., and M. A. Vanderwarn. 2001. Determination of moisture in cheese and cheese products. J. AOAC Int. 84:570-592.

Carlin, F., M. H. Guinebretiere, C. Choma, R. Pasqualini, A. Braconnier, and C. Nguyen-The. 2000. Spore-forming bacteria in commercial cooked, pasteurized and chilled vegetable purees. Food Microbiol. 17:153-165.

Cavanagh, D., G. F. Fitzgerald, and O. McAuliffe. 2015. From field to fermentation: The origins of Lactococcus lactis and its domestication to the dairy environment. Food Microbiol. 47:45-61.

Celandroni, F., S. Salvetti, S. A. Gueye, D. Mazzantini, A. Lupetti, S. Senesi, and E. Ghelardi. 2016. Identification and pathogenic potential of clinical Bacillus and Paenibacillus isolates. PLoS One 11:e0152831.

Dierick, K., E. Van Coillie, I. Swiecicka, G. Meyfroidt, H. Devlieger, A. Meulemans, G. Hoedemaekers, L. Fourie, M. Heyndrickx, and J. 
Mahillon. 2005. Fatal family outbreak of Bacillus cereus-associated food poisoning. J. Clin. Microbiol. 43:4277-4279.

EMEA (European Medicines Agency). 1995. ICH Topic Q 2, R1. Validation of Analytical Procedures: Note for guidance on validation of analytical procedures: text and methodology, CPMP/ICH/381/95.

Gálvez, A., R. L. López, H. Abriouel, E. Valdivia, and N. B. Omar. 2008. Application of bacteriocins in the control of foodborne pathogenic and spoilage bacteria. Crit. Rev. Biotechnol. 28:125-152.

Granum, P. E., S. Brynestad, and J. M. Kramer. 1993. Analysis of enterotoxin production by Bacillus cereus from dairy products, food poisoning incidents and non-gastrointestinal infections. Int. J. Food Microbiol. 17:269-279.

Guinebretiere, M. H., O. Berge, P. Normand, C. Morris, F. Carlin, and C. Nguyen-The. 2001. Identification of bacteria in pasteurized zucchini purees stored at different temperatures and comparison with those found in other pasteurized vegetable purees. Appl. Environ. Microbiol. 67:4520-4530.

Guinebretiere, M. H., H. Girardin, C. Dargaignaratz, F. Carlin, and C. Nguyen-The. 2003. Contamination flows of Bacillus cereus and spore-forming aerobic bacteria in a cooked, pasteurized and chilled zucchini purée processing line. Int. J. Food Microbiol. 82:223-232.

Guinebretiere, M.-H., and C. Nguyen-The. 2003. Sources of Bacillus cereus contamination in a pasteurized zucchini purée processing line, differentiated by two PCR-based methods. FEMS Microbiol. Ecol. 43:207-215

Guinebretiere, M. H., F. L. Thompson, A. Sorokin, P. Normand, P. Dawyndt, M. Ehling-Schulz, B. Svensson, V. Sanchis, C. NguyenThe, M. Heyndrickx, and P. De Vos. 2008. Ecological diversification in the Bacillus cereus group. Environ. Microbiol. 10:851-865.

Heyndrickx, M., and P. Scheldeman. 2002. Bacilli associated with spoilage in dairy and other food products. Pages 64-82 in Applications and Systematics of Bacillus and Relatives. R. Berkeley, M. Heyndrickx, N. A. Logan, P. De Vos, ed. Blackwell Science, Oxford, UK

ISO (International Organization for Standardization). 1998. Microbiology of food and animal feeding stuffs - Horizontal method for the enumeration of mesophilic lactic acid bacteria. Colony-count technique at 30 degrees C. ISO 15214:1998. ISO, Geneva, Switzerland.

ISO (International Organization for Standardization). 1999. Microbiology of food and animal feeding stuffs-Horizontal method for the enumeration of coagulase-positive staphylococci, Staphylococcus aureus and other species-Part 1: Technique using Baird-Parker agar medium. ISO 6888-1:1999. ISO, Geneva, Switzerland.

ISO (International Organization for Standardization). 2004. Microbiology of food and animal feeding stuff-Horizontal method for the enumeration of presumptive Bacillus cereus-Colony-count technique at 30 degrees C. ISO 7932:2004. ISO, Geneva, Switzerland.

ISO (International Organization for Standardization). 2009. Milk and milk products-Method for the enumeration of Pseudomonas spp. ISO/TS 11059|IDF/RM 225. ISO, Geneva, Switzerland.

Jameson, J. E. 1962. A discussion of the dynamics of Salmonella enrichment. J. Hyg. (Lond.) 60:193-207.

Kim, J., and P. M. Foegeding. 1990. Effects of heat-, $\mathrm{CaCl}_{2-}$ and ethanol-treatments on activation of Bacillus spores. J. Appl. Bacteriol. 69:414-420.

Lianou, A., and J. Samelis. 2014. Addition to thermized milk of Lactococcus lactis ssp. cremoris M104, a wild, novel nisin A-producing strain, replaces the natural antilisterial activity of the autochthonous raw milk microbiota reduced by thermization. J. Food Prot. 77:1289-1297.

Little, C. L., and S. Knøchel. 1994. Growth and survival of Yersinia enterocolitica, Salmonella and Bacillus cereus in Brie stored at 4, 8 and $20^{\circ} \mathrm{C}$. Int. J. Food Microbiol. 24:137-145.

Mellefont, L. A., T. A. McMeekin, and T. Ross. 2008. Effect of relative inoculum concentration on Listeria monocytogenes growth in co-culture. Int. J. Food Microbiol. 121:157-168.

Møller, C. O. A., S. Aabo, B. B. Christensen, P. Dalgaard, and T. B. Hansen. 2013. Effect of microflora on growth of Salmonella spp. in fresh pork-A predictive microbiology approach. Food Microbiol. $34: 284-295$

Montel, M. C., S. Buchin, A. Mallet, C. Delbes-Paus, D. A. Vuitton, N. Desmasures, and F. Berthier. 2014. Traditional cheeses: Rich and diverse microbiota with associated benefits. Int. J. Food Microbiol. 177:136-154.

Notermans, S., J. Dufrenne, P. Teunis, R. Beumer, M. te Giffel, and P. Peeters Weem. 1997. A risk assessment study of Bacillus cereus present in pasteurized milk. Food Microbiol. 14:143-151.

Østergaard, N. B., A. Eklöw, and P. Dalgaard. 2014. Modelling the effect of lactic acid bacteria from starter- and aroma culture on growth of Listeria monocytogenes in cottage cheese. Int. J. Food Microbiol. 188:15-25.

Passerini, D., V. Laroute, M. Coddeville, P. Loubière, P. Le Bourgeois, P. Ritzenthaler, M. Cocaign-Bousquet, and M.-L. DaveranMingot. 2013. New insights into Lactococcus lactis diacetyl- and acetoin-producing strains isolated from diverse origins. Int. J. Food Microbiol. 160:329-336.

Pu, Z. Y., M. Dobos, G. K. Y. Limsowtin, and I. B. Powell. 2002. Integrated polymerase chain reaction-based procedures for the detection and identification of species and subspecies of the Gram-positive bacterial genus Lactococcus. J. Appl. Microbiol. 93:353-361.

Røssland, E., G. I. Andersen Borge, T. Langsrud, and T. Sørhaug. 2003. Inhibition of Bacillus cereus by strains of Lactobacillus and Lactococcus in milk. Int. J. Food Microbiol. 89:205-212.

Røssland, E., T. Langsrud, P. E. Granum, and T. Sørhaug. 2005. Production of antimicrobial metabolites by strains of Lactobacillus or Lactococcus co-cultured with Bacillus cereus in milk. Int. J. Food Microbiol. 98:193-200.

Rukure, G., and B. H. Bester. 2001. Survival and growth of Bacillus cereus during Gouda cheese manufacturing. Food Control 12:3136.

Samelis, J., A. Lianou, A. Kakouri, C. Delbè, I. Rogelj, B. BogovicMatijasić, and M. C. Monte. 2009. Changes in the microbial composition of raw milk induced by thermization treatments applied prior to traditional Greek hard cheese processing. J. Food Prot. 72:783-790.

Senesi, S., G. Cercignani, G. Freer, G. Batoni, S. Barnini, and F. Ota. 1991. Structural and stereospecific requirements 366 for the nucleoside-triggered germination of Bacillus cereus spores. J. Gen. Microbiol. 137:399-404.

Senesi, S., and E. Ghelardi. 2010. Production, secretion and biological activity of Bacillus cereus enterotoxins. Toxins (Basel) 2:16901703

Soto del Rio, M. L. C. Andrighetto, A. Dalmasso, A. Lombardi, T. Civera, and M. T. Bottero. 2016. Isolation and characterization of lactic acid bacteria from donkey milk. J. Dairy Res. 83:383-386.

Spanu, C., C. Scarano, V. Spanu, C. Pala, D. Casti, S. Lamon, F. Cossu, M. Ibba, G. Nieddu, and E. P. L. De Santis. 2016. Occurrence and behavior of Bacillus cereus in naturally contaminated ricotta salata cheese during refrigerated storage. Food Microbiol. 58:135-138.

Svensson, B., K. Ekelund, H. Ogura, and A. Christiansson. 2004. Characterisation of Bacillus cereus isolated from milk silo tanks at eight different dairy plants. Int. Dairy J. 14:17-27.

Svensson, B., A. Eneroth, J. Bredehaug, and A. Christiansson. 1999 Investigation of Bacillus cereus contamination sites in a dairy plant with RAPD-PCR. Int. Dairy J. 9:903-912

Svensson, B., A. Eneroth, J. Brendehaug, G. Molin, and A. Christiansson. 2000. Involvement of a pasteuriser in the contamination of milk by Bacillus cereus in a commercial dairy plant. J. Dairy Res. 67:455-460.

Tirloni, E., P. Cattaneo, B. Ripamonti, A. Agazzi, C. Bersani, and S. Stella. 2014. In vitro evaluation of Lactobacillus animalis SB310, Lactobacillus paracasei ssp. paracasei SB137 and their mixtures as potential bioprotective agents for raw meat. Food Control 41:6368.

Tirloni, E., E. Ghelardi, F. Celandroni, C. Bernardi, R. Casati, P. S. Rosshaug, and S. Stella. 2017a. Bacillus cereus in fresh ricotta: 
Comparison of growth and Haemolysin BL production after artificial contamination during production or post processing. Food Control 79:272-278

Tirloni, E., E. Ghelardi, F. Celandroni, C. Bernardi, and S. Stella. 2017b. Effect of dairy products environment on the growth of $B a$ cillus cereus. J. Dairy Sci. 100:7026-7034.

Tirloni, E., S. Stella, L. V. de Knegt, G. Gandolfi, C. Bernardi, and M. J. Nauta. 2018. A quantitative microbial risk assessment model for Listeria monocytogenes in RTE sandwiches. Microb. Risk Anal. 9:11-21.

Tormo, M., and J. M. Izco. 2004. Alternative reversed-phase high-performance liquid chromatography method to analyse organic acids in dairy products. J. Chromatogr. A 1033:305-310.

Van Opstal, I., C. F. Bagamboula, S. C. M. Vanmuysen, E. Y. Wuytack, and C. W. Michiels. 2004. Inactivation of Bacillus cereus spores in milk by mild pressure and heat treatments. Int. J. Food Microbiol. 92:227-234.

Wong, H. C., L. Y. Chen, and C. L. Chen. 1988. Growth germination and toxigenic activity of Bacillus cereus in milk products. J. Food Prot. 51:707-710.

Wong, H. C., and Y. L. Chen. 1988. Effects of lactic acid bacteria and organic acids on growth and germination of Bacillus cereus. Appl. Environ. Microbiol. 54:2179-2184.

\section{ORCIDS}

Erica Tirloni @ https://orcid.org/0000-0002-2037-1875 